\title{
Overexpression of an aquaporin gene PVPIP2;9 increased biomass yield and protein content, improved drought tolerance and water use efficiency and affected other PIP2 genes' expression in switchgrass (Panicum virgatum L.)
}

Jing Zhang

Nanjing Agricultural University

Wuwu Wen

Nanjing Agricultural University

Hui Li

Nanjing Agricultural University

Qiyu Lu

Nanjing Agricultural University

Bin Xu ( $\sim$ binxu@njau.edu.cn )

Nanjing Agricultural University https://orcid.org/0000-0002-9701-7583

Bingru Huang

Rutgers The State University of New Jersey

\section{Research}

Keywords: Aquaporin, Drought, Water use efficiency, Protein content, Cellulose, Feedstock

Posted Date: May 15th, 2020

DOI: https://doi.org/10.21203/rs.2.19780/v2

License: (c) (i) This work is licensed under a Creative Commons Attribution 4.0 International License.

Read Full License 


\section{Abstract}

Background: Switchgrass ( Panicum virgatum L.) is a prime candidate for non-grain-based bioenergy feedstock production. Improved drought tolerance and higher water use efficiency are important for its successful field establishment and production, especially on marginal lands. Aquaporins are key channels and regulators for water transportation and maintenance of cellular water status. In this study, the functional role of an aquaporin gene, PvPIP2;9, in switchgrass was studied.

Results: Expression of PvPIP2;9 was regulated by diurnal oscillation and osmotic stress. Constitutive over-expressing PvPIP2;9 in switchgrass significantly improved its leaf length, plant height, above-ground biomass, biomass protein contents, and cellulose contents in stressed plants. Under 21 days of drought treatment, transgenic plants showed less electrolyte leakage rates, but higher relative water contents, photochemical efficiencies, and chlorophyll contents, indicating that PvPIP2;9 positively regulated plant drought tolerance and water use efficiency. Moreover, expression patterns of all 14 switchgrass PIP2 subfamily genes were checked during the drought treatment, and the result showed that over-expressing PvPIP2;9 also affected transcript levels of most other PIP2 genes.

Conclusions: Together, this study showed that improved biomass yield, drought tolerance and higher water use efficiency can be achieved by manipulating the expression level of PvPIP2;9 and also suggested PIP2 subfamily genes were transcriptionally regulated in a coordinated manner.

\section{Introduction}

Switchgrass (Panicum virgatum $\mathrm{L}$.) is a warm season tall perennial grass originated in North America and has been used as a pasture forage (1) and a non-grain-based bioenergy feedstock (2). A previous study showed that all tested switchgrass ecotypes suffered severe biomass reduction $(75-80 \%)$ with water stress at -4 MPa (3). To minimize competition with primary food crop production for land use, much of switchgrass production are on less productive marginal lands where irrigation is often limited or unavailable during prolonged drought periods. Therefore, improved drought tolerance and higher water use efficiency (WUE) are important targeting traits for switchgrass molecular breeding.

Aquaporin family genes play important regulatory roles in water movement through the symplastic pathway and maintenance of cellular water homeostasis in plants (4). Based on their sequence compositions, aquaporins can be divided into five types, including tonoplast intrinsic proteins (TIPs), nodulin 26-like intrinsic proteins (NIPs), small basic intrinsic proteins (SIPs), X-intrinsic proteins (XIPs), and plasma membrane intrinsic proteins (PIPs), among which PIPs might be the main gateways controlling water permeability (5). Furthermore, PIPs can be categorized into two phylogenetic subgroups, PIP1 and PIP2, according to their main structural differences. A number of PIP2s were found possessing high water channel activities and played indispensible roles in water transport $(6,7)$. Several individual studies have reported that over-expressing PIP2 subfamily genes improved plant drought tolerance, including FaPIP2; 1 in tall fescue (Festuca arundinacea) (8), PIP2;5 in Populus (Populus 
tremula $\times$ Populus alba) (9), TaAQP7 in wheat (Triticum aestivum) (10), and HvPIP2;1 in barley (Hordeum vulgare) (11). These results suggested that some PIP2 genes functioned as positive regulators in plant drought tolerance. Yet, in some other cases, over-expressing PIP2 genes compromised drought tolerance. For examples, over-overexpression of a soybean (Glycine soja) stress-inducible PIP2 gene (GsPIP2;1) in transgenic Arabidopsis (Arabidopsis thaliana) increased plant sensitivity to dehydration (12). Overexpression of PIP1;4 and PIP2;5 in both Arabidopsis and tobacco (Nicotiana tabacum) resulted in rapid water loss under dehydration stress as well as retarded seed germination and seedling growth under drought stress (13). Lee et al. (14) reported that activating an E3 ligase led to degradation of PIP2;1 and improved drought tolerance in Arabidopsis. In short, some PIP2s were functional in water transport, yet their roles in plant drought tolerance are diversified, and how these PIP2 family genes interacted and cooperated in maintaining plant water status was still unclear.

There are 68 aquaporin genes in switchgrass, including 7 PIP1 and 14 PIP2 subfamily members (15), and none of their functions has been characterized so far. In our previous study, over-expressing an Arabidopsis NAC transcriptional factor gene, LONG VEGETATIVE PHASE ONE (LOV1) in switchgrass resulted in smaller leaf angles, improved drought tolerance and higher WUE. Comparative microarray analysis revealed that there were 105 significantly differentially-expressed genes, among which PVPIP2;9 (microarray probe ID: KanlowCTG00810_at; Phytozyme accession No.: Pavir.Ba02478) was the only differentially-expressed and up-regulated aquaporin gene in the transgenic plants $(16,17)$. Therefore, we hypothesized that PVPIP2;9 plays an important role in the regulation of switchgrass drought tolerance. In the current work, the expression pattern and functional role of $P V P I P 2 ; 9$ in switchgrass drought tolerance were studied, and effects of drought and over-expression of PVPIP2;9 on other PIP2 family genes were also measured.

\section{Results}

\section{Phylogenetic analysis and expression pattern of PVPIP2;9}

According to the switchgrass genomic sequence information (Panicum virgatum v4.1, DOE-JGI, http://phytozome.jgi.doe.gov/), we cloned PVPIP2;9 from switchgrass. PvPIP2;9 had 286 amino acids with a predicted molecular mass of $29.87 \mathrm{kD}$. As a typical aquaporin protein, PvPIP2;9 had six conserved transmembrane (TM) domains and two nucleosome assembly protein (NAP) domains (Fig.1a). A phylogenetic tree comprising of PvPIP2;9 and its orthologs in rice (Oryza sativa), maize (Zea mays), and Arabidopsis showed that PvPIP2;9 was most closely related to OsPIP2; 4 with $97 \%$ of amino acid similarity (Fig. 1b).

At the organ/tissue level, the transcript level of PVPIP2;9 in roots was the highest, which was 6-10 times higher than those in leaves and leaf sheaths, and was 10-20 times higher than those in inflorescence of rachis, florets, vascular bundle, and internodes (Fig. 2a). In leaves, the expression of PVPIP2;9 showed a clear diurnal change that increased after dawn, reached to its maximum level in the middle of daytime and declined thereafter to its basal level at the end of the daytime (Fig. 2b). Furthermore, we measured its 
relative expression level in plants under 20\% PEG6000 (water potential: $-0.735 \mathrm{MPa}$ ) and $100 \mu \mathrm{M} \mathrm{ABA}$ treatments compared with the control sampled at the same time point. Treating switchgrass plants with PEG6000-induced osmotic stress resulted in significantly increased expression of the gene within $2 \mathrm{hr}$, and such an activated expression was transient that returned to its initial levels after 4 hrs of treatment and remained at its basal level thereafter (Fig. 2c). However, ABA treatment did not activate but suppressed the expression of PVPIP2;9 (Fig. 2d), indicating that the osmotic stress-induced expression of PVPIP2;9 was likely independent of the ABA signal.

\section{Over-expressing PVPIP2;9 led to improved drought tolerance, water use efficiency, higher biomass yield and crude protein contents in switchgrass}

The PVPIP2;9 was over-expressed in switchgrass under driven of the maize ubiquitin promoter by Agrobacterium-mediated genetic transformation. A total of 11 putative transgenic lines were generated. The presence of T-DNA in these putative lines was confirmed by PCR amplifying a fragment of HPTII gene (conferring hygromycin-resistance) (Fig. 3a). Three representative transgenic lines (line-1, -7 and -9) with over-expressed PVPIP2;9 and positive GUS staining signals (Fig. 3b\&C) were chosen for further phenotypic analyses.

Transgenic lines and tissue culture-regenerated WT plants of the same age were vegetatively propagated by splitting and growing single tillers under the optimum growth condition. After two and a half months of growth, single tillers of WT and the transgenic lines proliferated into five to seven tillers, and all PVPIP2;9-0X lines showed significantly longer leaf length, taller plant height, and higher above-ground biomass yield (fresh weight and dry weight) than those of WT (Table 1).

These switchgrass plants were treated by withdrawing water to evaluate whether over-expressing PVPIP2;9 affected drought tolerance. After 28 days of drought period, WT became severely wilted that even the newly emerged leaves at the top withered and turned yellow, while plants of all transgenic lines still remained 1-2 green leaves at the top in each tiller. After re-watering, WT plants did not recover but completely died off, while all PVPIP2;9-0X lines recovered back with new green expanding leaves (Fig. $5 a)$. During the drought treatment, the pot soil water content dropped from -0.48 MPa to $-0.83 \sim-0.85 \mathrm{Mpa}$, $-1.35 \sim-1.20 \mathrm{MPa}$, and -1.65 MPa after 7, 14, 21 and 28 days of water withdrawal, respectively, while those under well-watered condition had a relative constant soil water content of -0.48-0.5 MPa (Fig. 5b). Five physiological parameters, including photochemical efficiency ( $\mathrm{Fv} / \mathrm{Fm})$, chlorophyll (Chl) content, electrolyte leakage (EL), leaf relative water content (RWC), and WUE were measured in WT and transgenic lines during the drought treatment. As shown in figure $5 \mathrm{c}-\mathrm{g}$, there was no significant difference among these physiological parameters between WT and PVPIP2;9-OX lines when under the well-watered condition. Yet, under the drought treatment, significant differences were observed after 21 days of treatment for all five physiological parameters that transgenic plants had significantly lower EL, but higher RWC, Fv/Fm, Chl contents and WUE than those of the WT (Fig. 5c-g). WUE of plants after 28 days of water holding was not measured because leaves of WT were completely wilted already. Furthermore, values of WUE, EL and RWC of the transgenic lines were also related to their relative expression of 
PVPIP2;9. For example, transgenic line-7 had the highest expression level of PVPIP2;9 in leaves, while line1 had the least. After 28 days of drought treatment, line-7 showed the lowest EL and the highest RWC, while the opposite was true for line-1. These results supported that over-expressing PVPIP2;9 significantly improved switchgrass drought tolerance and WUE associated with higher photochemical efficiency, higher membrane stability, higher $\mathrm{Chl}$ content, and better leaf water status under this prolonged stress.

To understand whether over-expressing PVPIP2;9 also affected biomass feedstock quality, we measured total sugar, cellulose, hemicellulose, lignin and crude protein contents in above-ground biomass of WT and transgenic lines. As shown in table 2, all transgenic lines had significantly higher crude protein content than WT no matter the plants were grown under the optimum soil water or after 21 days of drought. It is also notable that the tested plants showed varied levels of total sugar, cellulose, hemicelluloses and lignin under the optimum soil water condition; yet after 21 days of drought, transgenic lines had significantly higher cellulose.

\section{Over-expression of PVPIP2;9 affected expression patterns of other PIP2 genes during drought treatment}

To understand whether over-expressing PVPIP2;9 also affected other PIP2 subfamily genes, we further measured relative expression levels of all PVPIP2 genes during the water-withdrawal treatment in WT and the three transgenic plants.

Firstly, it was notable that expression of $P V P I P 2 ; 9$ per se was responsive to the long-term drought stress but was distinctively different in leaves and roots: the relative expression of PVPIP2;9 increased $\sim 3$ times in WT leaves, but reduced to $20 \%$ in WT roots during the drought treatment. While in transgenic lines, relative expression levels of PVPIP2;9 were $\geq 200$ times higher than those of WT in leaves, and $\geq 2$ times higher than those of WT in roots (the only exception was that in line- 1 and -7 before drought treatment where they were at similar expression levels to that in WT). Yet, during the drought treatment, expression levels of PVPIP2;9 decreased in leaves but gradually increased 6-13 folds in roots in the two transgenic lines (Fig. 6).

Secondly, as shown in WT, most PIP2 subfamily genes were responsive to the drought treatment. For examples, transcriptional levels of $P v P I P 2 ; 3$, PVPIP2;4, and PVPIP2;5 increased in response to decreasing soil water content in both leaves and roots; while those of PVPIP2;11 and PVPIP2;13 showed increased expression pattern only in roots but not in leaves (Fig. 7).

Thirdly, by comparing gene expression patterns in WT and in transgenic lines, we found that expression of most PIP2 family genes were affected by the over-expression of PVPIP2;9. For examples, in leaves of transgenic lines, one (PVPIP2;8) showed higher expression levels and five (PVPIP2;2, PVPIP2;5, PVPIP2;12, PVPIP2;13, and PVPIP2;14) showed lower expression levels than those in WT. While in roots of transgenic lines, five PVPIP2 genes (PVPIP2;1, PvPIP2;4, PVPIP2;6, PVPIP2;7, and PVPIP2;8) showed significantly higher and one ( $P V P I P 2 ; 14)$ showed lower expression patterns along with the decreasing soil water content (Fig. 7). 


\section{Discussion}

There are 68 aquaporin genes in switchgrass (15). Yet none of these genes was functionally characterized so far. Based on our previous study, we predicted that PvPIP2;9 might be an important aquaporin contributing to the leaf water status in switchgrass. Current results in this study indicate that PVPIP2;9 positively regulated switchgrass drought tolerance and WUE.

\section{PvPIP2;9 is an important aquaporin regulating plant water status in switchgrass}

Under drought treatment, transgenic switchgrass demonstrated significantly improved drought tolerance and WUE under this prolonged drought stress. The association between aquaporin genes' expression and WUE has been documented before. For examples, over-expressing a stress-inducible aquaporin gene (NaAQP1) in tobacco, tomato (Lycopersicon esculentum) and Arabidopsis all increased their WUE and photosynthesis under both optimal and salt stress conditions (18). And over-expressing a TIP-type aquaporin (AQUA1) in white poplar (Populus alba) also improved the plant's WUE and RWC (19). In this study, we found transgenic plants had significantly higher WUE associated with lower EL, higher Fv/Fm, Chl content, and RWC than WT after prolonged drought treatment (Fig. 5). Lower EL value indicated better cell membrane integrity, higher Fv/Fm and Chl content further corroborated that leaves of transgenic plants were bringing their functions into better play, and the higher RWC in transgenic plants confirmed that PvPIP2;9 positively contributed to cellular water status of leaves when the soil water content was low. We reasoned that the higher WUE in transgenic plants should be another important reason for the improved drought tolerance that saved water loss from evapotranspiration, which in turn contributed to better cellular water status as reflected in leaf RWC and the maintenance of integral cell membrane system and photosynthesis system.

\section{Expression level of PVPIP2;9 affected plant growth and biomass feedstock quality in switchgrass}

Under the well-watered condition, constitutive over-expression of PVPIP2;9 in switchgrass did not significantly alter the WUE and leaf relative water content though, suggesting that over-expressing of this aquaporin gene did not significantly affect water transportation or water status when there was sufficient soil water supply. Yet, transgenic lines did show significantly longer leaf length, taller plant height and higher above-ground biomass than those of WT. Another interesting finding with the transgenic switchgrass was their higher protein contents no matter they were grown under the optimum or drought condition, and showed significantly higher cellulose content after 21 days of drought. The higher biomass protein content was not essential for lignocellulosic biofuel feedstock but was a highly desirable trait when switchgrass was used as forage feedstock. To our knowledge, such an effect on biomass protein and cellulose contents was not well emphasized or recorded for a PIP gene before.

It was reported that leaf elongation rate responded to rapid changes in evaporation and soil water availability in an even considerably quicker manner than transpiration and leaf water potential (e.g. 30 min vs. 1-2 h), and small flux of water potentials could cause rapid decline of simulated leaf elongation rate (20). Nada \& Abogadallah (21) reported that reduced WUE and decreased RWC at mid-day in rice 
even under well-watered paddy field which was associated with inadequate expression of aquaporin genes, and such an suppression could be eliminated upon removal of radial barriers to water flow in roots. We reasoned that these WT and transgenic plants be challenged by temporary water deficit (e.g. at noon time) even though they were regularly watered and grown under optimum condition in greenhouse. While due to the effect of PVPIP2;9 over-expression, transgenic plants were less challenged with temporary fluxes of unfavorable leaf water potential. Decades earlier, effect of water stress on protein contents in maize cultivars with contrasting drought tolerance has been reported that the drought tolerant cultivar showed higher protein contents than the susceptible one (22). Effects of short-term drought (4 or 7 days of drought) in switchgrass (23) and long-term drought (28 days) in miscanthus (24) were reported that their cell wall components were affected by drought stress to various degrees. For example, cellulose content was significantly lower in drought treated miscanthus (24). The relatively higher cellulose content in stressed PVPIP2;9 transgenic switchgrass was at least partially explained by the better plant water status during the drought treatment.

Another possible reason for the plant growth effect of the transgene could be due to other beneficial growth-promoting effect of PvPIP2;9. It was reported that OsPIP2;4 contributed to plant boron tolerance (Kumar et al., 2014) and might have the capability of transporting non-aqua substrates $\mathrm{CO}_{2}$ as well as $\mathrm{H}_{2} \mathrm{O}_{2}$ (Azad et al., 2016). Further investigation on whether PvPIP2;9 was involved in transportation of other molecules is warranted in the future.

\section{PVPIP2;9 and other PVPIP2 subfamily genes were fine-tuned and interacted at the transcriptional level}

OsPIP2;4 was the closest rice orthologous gene of PvPIP2;9. Although it is still unclear whether OsPIP2;4 plays a regulatory role in plant drought tolerance or not, it was reported that the expression of OSPIP2;4 showed a clear diurnal expression pattern and OsPIP2;4 had high water channel activity (6). PVPIP2;9 also had a similar expression pattern to OsPIP2;4 that its diurnal transcription level was in conjunction with the activity of plant diurnal water transport. The diurnal changes of aquaporin genes have also been reported for a few other PIP2 genes in other plant species, such as HVPIP2;1 in barley (25), ZmPIP2;1 and $Z m P I P 2 ; 5$ in maize (25), and OsPIP2;4 and OsPIP2;5 in rice (6). Such an expression pattern suggested that water uptake in leaves during the daytime demand higher transcriptional level of this aquaporin gene. Furthermore, the expression of $P V P I P 2 ; 9$ in leaves was transiently up-regulated by osmotic stress, but down-regulated by exogenous applied ABA treatment in leaves. Dehydration caused difficulty in root water absorption with lower osmotic potential in the first place, and caused less water evapotranspiration rate by inducing stomata closure and induced ABA production at a later stage (26). The transiently increased expression of PVPIP2;9 upon PEG-treatment could be a direct response to the water-deficit due to PEG-induced shortage of root water absorption. And the ABA-induced suppression of PVPIP2;9 in leaves could be due to the quick response of stomata closure that in turn helped balancing leaf water status. In short, the expression pattern of PVPIP2;9 was highly responsive to plant water status, which was in congruent with the gene's function in the regulation of plant water status, indicating that regulation of the PIP2 gene at the transcription level was important for switchgrass. 
Upon the recognition of PIPs' contributions to water transport and cellular water homeostasis, there is an interest to understand the full picture of how these PIPs interacted and coordinated with each other in these cellular processes. From the perspective of the protein-protein interactome, previous studies on two maize PIP1 and three PIP2 subfamily genes showed that ZmPIP1;1 and ZmPIP1;2 could form heterodimers but showed no activity of osmotic water permeability (27); yet this ZmPIP1-ZmPIP2 interaction was required for PIP1 trafficking to plasma membrane (28). At the same time, such physical interaction between PIP1-PIP2 (e.g. ZmPIP1;2-ZmPIP2;1) was required for their functions to form consolidated water channels (27). A more recent work studying on interactomes of PIP1;2 and PIP2;1 proteins, using the approach of immunoprecipitation and quantification by mass spectrometry (IP-MS), revealed that these two proteins shared about 400 interacting proteins (29). This big interacting protein mass likely behaved as a "platform" for recruitment of various proteins likely involved in transport activities including those responding to osmotic and oxidative treatments (29). At the post-translational level, 12 out of 13 Arabidopsis PIPs were found to have varied types of post-translational modifications including phosphorylation, methylation, deamidation, and acetylation in response to environmental stress (30). Meanwhile, at the post-transcriptional level, it was reported that microRNAs (miRNAs) were endogenous modulators of multiple aquaporin genes in human (31). Another study in Arabidopsis also reported that salinity treatment invoked a simultaneous transcriptional repression and protein internalization of PIP2;7(32). Yet, it was less recognized that, at transcriptional level, expression of these PIP2 genes were also inter-affected. There are 14 PVPIP2 genes in switchgrass in reference to the current switchgrass genome database ("Panicum virgatum v4.1, DOE-JGI, http://phytozome.jgi.doe.gov/"). In this study, we found that over-expressing PVPIP2;9 in switchgrass significantly affected expression of many other PIP2 genes (Fig. 7). We reasoned these changes of other PIP2 genes at the transcriptional level might be due to feedback effect of cellular status in the transgenic plants because of potential functional redundancy between these PIP2 genes, or due to post-transcriptional regulation of PIP2 genes (e.g. targeted by miRNA on certain common sequence among these PIP2 genes), which was yet to be studied in the future. Overall, our current results indicate that there was a complicated interacting network of PIP2s at the transcriptional level as well. Together with previous findings, PIPs likely responded to environmental constraints at multiple levels of gene regulation to adjust plant water status.

As mentioned earlier, PVPIP2;9 was the only aquaporin gene with significantly increased expression in the LOV1 transgenic plants that showed improved drought tolerance $(16,17)$. We also tested whether or not the LOV1 transcription factor could directly bind to the $-2 \mathrm{~Kb}$ promoter region of $P V P I P 2 ; 9$ using yeast onehybrid test. However, our results showed that there was no transactivation effect of LOV1 on the PVPIP2;9 promoter (data not shown), suggesting that LOV1 indirectly activated the expression of PVPIP2;9 in switchgrass.

\section{Conclusion}

A PIP2 gene was cloned and functionally characterized for the first time in switchgrass in this study. PvPIP2;9 positively contributed to plant water status, enhanced plant protein contents of above-ground biomass, and significantly improved switchgrass cellulose contents, drought tolerance, and WUE in 
stressed plants. Moreover, the result together with previous reports supported that PIP2s were coordinately regulated at multiple levels, including transcriptional, post-transcriptional and posttranslational levels, to adjust plant water status. Results of this study highlight the importance of the aquaporin gene, PVPIP2;9, and the complexity of PIP2 family genes in the regulation of switchgrass water status. Such information will be useful for switchgrass molecular breeding toward improved drought tolerance and higher WUE.

\section{Methods}

\section{Plant materials and growth condition}

Seeds of an elite switchgrass line, HR8, originally selected from the lowland ecotype 'Alamo' was used in this study (33). In the qPCR experiment to study PVPIP2;9 expression pattern, 4-wk-old plants were cultured in 1/2 Hoagland solution and grown in a growth chamber with a 12-hour (hr) light/dark cycle and accurately controlled temperature $\left[30 / 25^{\circ} \mathrm{C}\right.$ (day/night)] and light intensity (photosynthetically active radiation at $750 \mu \mathrm{mol}$.photons $\mathrm{m}^{-2} \cdot \mathrm{s}^{-1}$ ). In other experiments, switchgrass plants were grown in grown in clay loam soil mixed with sand $(1: 1)$ in $1.1 \times 10^{-2} \mathrm{~m}^{3}$ pots in the greenhouse at Nanjing Agricultural University (Nanjing, China) with temperatures set at $30 / 20 \pm 3{ }^{\circ} \mathrm{C}$ (day/night) and the photoperiod set at $14 / 10 \mathrm{hr}$ (day/night).

\section{qRT-PCR analysis}

The second fully expanded leaves from the top were sampled for relative gene expression level and physiological parameter analyses. To detect the diurnal oscillation of PVPIP2;9, the first sampling time was set at the dawn for consecutive $40 \mathrm{hr}$ with four hr internals in-between. For stress treatments, plants were grown in 1/2 Hoagland solution containing 20\% polyethylene glycol (PEG) 6000 (Huada, Shantou, China) and $100 \mu \mathrm{M}$ ABA according to Yuan et al. (34), and sampled after 0, 0.5, 1, 2, 4, 8 and $12 \mathrm{hr}$ after the treatment.

The total RNA was isolated using OMEGA E.Z.N.A. ${ }^{\circledR}$ plant RNA Kit. The first strand cDNA was synthesized with $1 \mu \mathrm{g}$ RNA using the PrimeScript ${ }^{\mathrm{TM}} \mathrm{RT}$ reagent Kit (Takara, Dalian, China) with the Perfect Real Time gDNA Eraser (TaKaRa). The qRT-PCR was performed using SYBR Green Master Mixes on a Roche LightCycler ${ }^{\circledR} 480$ II machine. The qRT-PCR was performed with three biological replicates and two technical replicates, and the qPCR program set as follows: $10 \mathrm{~min}$ at $95^{\circ} \mathrm{C}$ for initial denaturation, and 40 cycles $\left(95^{\circ} \mathrm{C}\right.$ for $15 \mathrm{~s}, 58^{\circ} \mathrm{C}$ for $15 \mathrm{~s}$, and $72{ }^{\circ} \mathrm{C}$ for $20 \mathrm{~s}$ ). Relative expression levels of PVPIP2;9 were calculated using the $2^{-\triangle \triangle C T}$ method with $P V A C T I N$ as the reference gene (35). Primers used in this study were shown in Additional file 1: Table S1.

\section{Gene cloning and vector construction}

According to the switchgrass genomic sequence information (Panicum virgatum v4.1, DOE-JGI, http://phytozome.jgi.doe.gov), we cloned the gene from gDNA for its functional characterization. In brief, 
the gene was amplified from switchgrass genomic DNA using PCR, cloned into the vector pENTR/D and sequenced. Then we sub-cloned the gene into the Gateway-compatible binary vector pVT1629 (35) using LR reaction (Invitrogen). The resultant vector, pVT1629-PvPIP2;9, harboring the PVPIP2;9 driven under maize ubiquitin promoter and the UidA (GUS) reporter gene under CaMV 35 S promoter, was transformed into the Agrobacterium tumefaciens strain ' $A G L 1$ ' through electroporation.

\section{Switchgrass genetic transformation}

Switchgrass line 'HR8' was used for Agrobacterium-mediated genetic transformation and the transformation procedure was the same as reported before (33). Hygromycin B (Sigma) at $50 \mathrm{mg} / \mathrm{L}$ was used to select against the non-transformed calli. Regenerated plants from independent calli were regarded as putative transgenic lines which were further verified by GUS staining and PCR for the detection of HPT\& gene present in the T-DNA.

\section{Drought treatment of WT and transgenic plants}

Two independent transgenic lines and tissue culture-regenerated wild-type (WT) plants were propagated by splitting single tillers grown at the optimum condition. Plants grown from a single tiller for two and a half months reached E4 stage (36) and were used for drought treatment by withdrawing water. After 28d of drought, the treated plants were re-watered to observe their re-growth status. At the same time period, normally-watered plants were used as controls. A soil water content detector (Mini Trase Kit 6050X3; Soil Moisture Equipment Corp., Santa Barbara, CA) was used to monitor the soil water content (SWC) in 0-8 $\mathrm{cm}$ deep soil layer of each pot. And soil water potential was determined using ERS- $₫$ water potential and temperature meter (Yibaiyi Mechanical and Electrical Equipment Co., Ltd., Wenzhou, China). The correlation between soil water content and soil water potential was shown in Additional file 2: Figure S1.

\section{Biomass feedstock quality analysis}

After $21 \mathrm{~d}$ of treatment, the above ground of WT and transgenic plants were collected and dried in a $70^{\circ} \mathrm{C}$ oven and then ground for feedstock quality analysis. The amount of total sugar was determined by the phenol sulfuric acid reagent method (37) with slight modifications. In brief, $0.05 \mathrm{~g}$ samples were added to

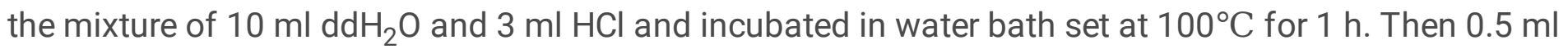
supernatant was transferred to a $10 \mathrm{ml}$ tube and mixed with $0.5 \mathrm{ml} \mathrm{ddH}_{2} \mathrm{O}, 1 \mathrm{ml} 5 \%$ phenol, and $5 \mathrm{ml}$ sulfuric acid. The reaction mixture was incubated at $30^{\circ} \mathrm{C}$ for $20 \mathrm{~min}$ in a water bath and then the absorbance was quantified at $490 \mathrm{~nm}$. The quantity of total sugar was based on a standard curve generated with known sugar concentrations.

Cellulose content was estimated using the anthrone method (38). Briefly, $0.05 \mathrm{~g}$ samples were mixed with $35 \mathrm{ml} 60 \% \mathrm{H}_{2} \mathrm{SO}_{4}$ in a $50 \mathrm{ml}$ tube and incubated at ice bath for $30 \mathrm{~min}$. After ten times dilution, the absorbance of supernatant was quantified at $620 \mathrm{~nm}$. Microcrystalline cellulose (Avicel) was used as a standard for the standard curve generation. 
Hemicellulose and lignin content were measured by hydrochloric acid hydrolysis method and sulfuric acid method, respectively (39). For hemicellulose analysis, $0.1 \mathrm{~g}$ sample was mixed with $10 \mathrm{ml} 80 \%$ calcium nitrate and boiled on a heater for $5 \mathrm{~min}$. The mixture was then centrifuged and the supernatant was discarded. After rinsed three times with $\mathrm{ddH}_{2} \mathrm{O}, 10 \mathrm{ml} 2 \mathrm{M} \mathrm{HCl}$ was added to the mixture and boiled for another $45 \mathrm{~min}$. The supernatant was neutralized using $\mathrm{NaOH}$ and mixed with DNS reagent. The mixture was incubated in water bath at $100^{\circ} \mathrm{C}$ for $5 \mathrm{~min}$ and then absorbance of supernatant was measured at $520 \mathrm{~nm}$. For lignin, $0.1 \mathrm{~g}$ sample was washed using $10 \mathrm{ml} 1 \%$ acetic acid and the mixture of ethanol and ether $(1: 1)$ and then was dried in a water bath set at $100^{\circ} \mathrm{C}$. The sample was incubated with $72 \% \mathrm{H}_{2} \mathrm{SO}_{4}$ for at least for $16 \mathrm{~h}$ to remove cellulose. The precipitate was then mixture with $10 \mathrm{ml} 10 \%$ $\mathrm{H}_{2} \mathrm{SO}_{4}$ and $0.1 \mathrm{M}$ potassium dichromate and incubated in water bath set at $100^{\circ} \mathrm{C}$ for $15 \mathrm{~min}$. The lignin content was then quantified after mixed with $5 \mathrm{ml} 20 \% \mathrm{KI}$ and $1 \mathrm{ml} 0.5 \%$ starch solution by titration using $0.2 \mathrm{M}$ sodium thiosulfate.

The Kjeldahl procedure was used to determine the total nitrogen (TN) content, and the crude protein content was calculated by multiplying TN by 6.25 (40).

\section{Measurement of physiological parameters}

Leaf membrane stability was evaluated by measuring the electrolyte leakage (EL) (41) according to a method described before (42). In brief, leaves were excised and cut into $3 \mathrm{~cm}$ segments. Then the leaves were incubated in $35 \mathrm{ml}$ distilled deionized water. Centrifuge tubes were shaken on a shaker for $24 \mathrm{hr}$ at room temperature, and the initial level of EL $\left(C_{i}\right)$ was measured using a conductance meter (Thermo Scientific, Beverly, USA).Then the leaf tissue was killed by autoclaving at $121^{\circ} \mathrm{C}$ for $15 \mathrm{~min}$, and then incubated for $24 \mathrm{~h}$ on a shaker for measuring the maximum conductance $\left(\mathrm{C}_{\max }\right)$ of the solution. Relative EL was calculated as $E L=\left(C_{i} / C_{\max }\right) \times 100 \%$.

The leaf relative water content (RWC) was determined according to the method described by Hu et al. (43) with modifications. In brief, RWC was determined using fresh fully expanded leaves $(\sim 0.2 \mathrm{~g})$. Leaf samples were detached from the plants and immediately weighed to determine the fresh weight (FW). Samples were placed into covered centrifuge tubes filled with water for leaves to reach full hydration. After approximately $24 \mathrm{~h}$ at $4{ }^{\circ} \mathrm{C}$, leaf samples were blotted dry with paper towels and weighed to determine the saturated weight (SW). Leaf tissue was then dried in an oven at $65^{\circ} \mathrm{C}$ for $72 \mathrm{hr}$ to determine dry weight $(D W)$. Leaf RWC was calculated as RWC $=(F W-D W) /(S W-D W) \times 100$.

The ratio of the variable fluorescence $(F v)$ to the maximal fluorescence $(F \mathrm{~m})(F \mathrm{v} / F \mathrm{~m})$ was used to represent leaf photochemical efficiency (Oxborough and Baker, 1997). The Fv/ Fm ratio was determined using a fluorescence meter (Dynamax, Houston, TX, USA) as described before (42). And chlorophyll content were measured using the DMSO extraction method as described before (42).

Leaf instantaneous WUE was calculated by measuring leaf net photosynthetic rate $(\mathrm{Pn})$ and transpiration rate (Tr) using the LI-6400 portable photosynthesis system (LI-COR, Lincoln, NE). The area of leaves 
enclosed in the leaf chamber was determined on a scanner, which was then used to calculate the $\mathrm{Pn}$ and Tr values. The WUE was calculated as Pn/Tr.

\section{Statistical analysis}

Data in this study were statistically analyzed using one-way ANOVA, and their means were compared by Duncan test at the significance level of 0.05 by using SPSS20.0.

\section{Tables}

Table 1. Over-expression of PvPIP2;9 affected above-ground growth of WT and transgenic plants. Three independent transgenic lines and tissue culture-regenerated wild-type (WT) plants were propagated by splitting single tillers grown at the optimum condition for two and a half months reached E4 stage. Then the tiller number, leaf width, leaf length, and plant height were measured. The above ground fresh and dry weight were tested from those plants after another 28 days growth. Data are means \pm SE $(n=8)$, and different letters represent significant difference at $\mathrm{P}<0.05$.

\begin{tabular}{|c|c|c|c|c|c|c|}
\hline & $\begin{array}{l}\text { Tiller } \\
\text { number }\end{array}$ & $\begin{array}{l}\text { Leaf width } \\
\text { (cm) }\end{array}$ & $\begin{array}{l}\text { Leaf length } \\
\text { (cm) }\end{array}$ & $\begin{array}{l}\text { Plant height } \\
\text { (cm) }\end{array}$ & $\begin{array}{l}\text { Above ground fresh } \\
\text { weight }(\mathrm{g})\end{array}$ & $\begin{array}{l}\text { Above ground dry } \\
\text { weight }(\mathrm{g})\end{array}$ \\
\hline WT & $\begin{array}{l}5.00 \pm \\
0.38 \mathrm{~b}\end{array}$ & $\begin{array}{l}0.90 \pm \\
0.011 \mathrm{a}\end{array}$ & $\begin{array}{l}43.19 \pm \\
0.83 \mathrm{~b}\end{array}$ & $\begin{array}{l}100.54 \pm \\
0.21 c\end{array}$ & $31.66 \pm 1.41 \mathrm{c}$ & $6.60 \pm 0.28 c$ \\
\hline $\begin{array}{l}\text { Line } \\
1\end{array}$ & $\begin{array}{l}6.78 \pm \\
0.70 \mathrm{a}\end{array}$ & $\begin{array}{l}0.90 \pm \\
0.045 \mathrm{a}\end{array}$ & $\begin{array}{l}47.37 \pm \\
0.64 \mathrm{a}\end{array}$ & $\begin{array}{l}110.03 \\
\pm 3.39 \mathrm{ab}\end{array}$ & $42.26 \pm 1.64 \mathrm{a}$ & $9.01 \pm 0.31 \mathrm{a}$ \\
\hline $\begin{array}{l}\text { Line } \\
7\end{array}$ & $\begin{array}{l}5.13 \pm \\
0.30 b\end{array}$ & $\begin{array}{l}0.88 \pm \\
0.003 a\end{array}$ & $\begin{array}{l}47.11 \pm \\
0.79 \mathrm{a}\end{array}$ & $\begin{array}{l}113.92 \pm \\
1.47 \mathrm{a}\end{array}$ & $36.14 \pm 1.33 b$ & $7.68 \pm 0.30 b$ \\
\hline $\begin{array}{l}\text { Line } \\
9\end{array}$ & $\begin{array}{l}6.89 \pm \\
0.32 \mathrm{a}\end{array}$ & $\begin{array}{l}0.88 \pm \\
0.003 \mathrm{a}\end{array}$ & $\begin{array}{l}46.78 \pm \\
0.88 \mathrm{a}\end{array}$ & $\begin{array}{l}105.43 \pm \\
0.30 b\end{array}$ & $40.30 \pm 1.71 \mathrm{ab}$ & $8.16 \pm 0.23 a b$ \\
\hline
\end{tabular}

Table 2. Over-expression of PvPIP2;9 affected biomass feedstock quality. The biomass were harvested from plants after 21 days of drought treatment or under the optimum growth condition (control). Data are means \pm SE $(n=3)$, and different letters represent significant difference at $\mathrm{P}<0.05$.

\begin{tabular}{llllll}
\hline & Sugars (\%) & Cellulose (\%) & Hemicellulose (\%) & Lignin (\%) & Crude protein (g/kg) \\
\hline Control-WT & $59.44 \pm 2.84 \mathrm{a}$ & $21.40 \pm 0.25 \mathrm{a}$ & $57.06 \pm 4.28 \mathrm{a}$ & $20.90 \pm 1.27 \mathrm{~b}$ & $93.83 \pm 0.61 \mathrm{~g}$ \\
Control-line 1 & $47.66 \pm 1.41 \mathrm{~b}$ & $19.96 \pm 0.32 \mathrm{bc}$ & $52.01 \pm 0.49 \mathrm{bc}$ & $22.71 \pm 1.47 \mathrm{a}$ & $114.55 \pm 1.31 \mathrm{f}$ \\
Control-line 7 & $56.52 \pm 1.42 \mathrm{a}$ & $20.16 \pm 0.19 \mathrm{~b}$ & $50.70 \pm 0.57 \mathrm{bc}$ & $20.72 \pm 0.25 \mathrm{~b}$ & $110.24 \pm 0.80 \mathrm{~d}$ \\
Control-line 9 & $51.97 \pm 1.61 \mathrm{ab}$ & $19.55 \pm 0.19 \mathrm{~cd}$ & $48.25 \pm 0.92 \mathrm{bc}$ & $20.80 \pm 0.32 \mathrm{~b}$ & $105.47 \pm 0.48 \mathrm{e}$ \\
Drought-WT & $46.20 \pm 2.16 \mathrm{~b}$ & $16.40 \pm 0.21 \mathrm{~g}$ & $50.82 \pm 3.21 \mathrm{bc}$ & $18.33 \pm 0.33 \mathrm{c}$ & $71.40 \pm 1.25 \mathrm{~d}$ \\
Drought-line 1 & $48.69 \pm 3.66 \mathrm{~b}$ & $18.23 \pm 0.29 \mathrm{f}$ & $52.36 \pm 5.05 \mathrm{ab}$ & $19.35 \pm 0.28 \mathrm{c}$ & $82.73 \pm 0.55 \mathrm{a}$ \\
Drought-line 7 & $58.03 \pm 5.56 \mathrm{a}$ & $19.27 \pm 0.37 \mathrm{de}$ & $45.48 \pm 3.11 \mathrm{c}$ & $21.27 \pm 0.28 \mathrm{~b}$ & $92.76 \pm 0.56 \mathrm{~b}$ \\
Drought-line 9 & $57.72 \pm 8.22 \mathrm{a}$ & $18.88 \pm 0.43 \mathrm{e}$ & $46.77 \pm 4.15 \mathrm{ab}$ & $22.58 \pm 0.32 \mathrm{a}$ & $86.88 \pm 0.62 \mathrm{c}$ \\
\hline
\end{tabular}




\section{Additional Files}

Additional file 1: Table S1 Primers used in this study.

Additional file 2: Figure S1 Correlation between soil water content and soil water potential for the potting soil used in this study.

\section{Declarations}

\section{Ethics approval and consent to participate}

Not applicable

\section{Consent for publication}

All authors consent for publication.

\section{Availability of data and materials}

All data generated or analyzed in the present study are included in this published article and in additional information.

\section{Competing interests}

The authors have no conflict of interest to declare.

\section{Funding information}

This study was supported by grant 31772659 from the National Natural Science Foundation of China, and by grant 2017M621764 from the China Postdoctoral Science Foundation.

\section{Authors' contributions}

BX, ZJ and BH designed the experimental studies; BX and ZJ wrote the manuscript; ZJ, WW, HL, and QL conducted experiments; ZJ, WW, HL and BX analyzed data. All authors read and approved the final manuscript.

\section{Acknowledgments}

We thank the anonymous reviewers for critical comments on the manuscript.

\section{References}

1. Anderson B, Ward JK, Vogel KP, Ward MG, Gorz HJ, Haskins FA. Forage quality and performance of yearlings grazing switchgrass strains selected for differing digestibility. Journal of Animal Science. 
1988;66(9):2239-44.

2. Sanderson MA, Read JC, Reed RL. Harvest management of switchgrass for biomass feedstock and forage production. Agronomy Journal. 1999;91(1):5-10.

3. Barney JN, Mann JJ, Kyser GB, Blumwald E, Van Deynze A, DiTomaso JM. Tolerance of switchgrass to extreme soil moisture stress: Ecological implications. Plant Science. 2009;177(6):724-32.

4. Zargar SM, Nagar P, Deshmukh R, Nazir M, Wani AA, Masoodi KZ, et al. Aquaporins as potential drought tolerance inducing proteins: Towards instigating stress tolerance. Journal of Proteomics. 2017;169:233-8.

5. Yaneff A, Vitali V, Amodeo G. PIP1 aquaporins: intrinsic water channels or PIP2 aquaporin modulators? FEBS letters. 2015;589(23):3508-15.

6. Sakurai J, Ishikawa F, Yamaguchi T, Uemura M, Maeshima M. Identification of 33 rice aquaporin genes and analysis of their expression and function. Plant and Cell Physiology. 2005;46(9):1568-77.

7. Kammerloher W, Fischer U, Piechottka GP, Schäffner AR. Water channels in the plant plasma membrane cloned by immunoselection from a mammalian expression system. The Plant Journal. $1994 ; 6(2): 187-99$.

8. Zhuang L, Liu M, Yuan X, Yang Z, Huang B. Physiological effects of aquaporin in regulating drought tolerance through overexpressing of Festuca arundinacea aquaporin gene FaPIP2; 1 . Journal of the American Society for Horticultural Science. 2015;140(5):404-12.

9. Ranganathan K, Cooke JEK, El Kayal W, Equiza MA, Vaziriyeganeh M, Zwiazek JJ. Over-expression of PIP2;5 aquaporin alleviates gas exchange and growth inhibition in poplars exposed to mild osmotic stress with polyethylene glycol. Acta Physiologiae Plantarum. 2017;39(8):187.

10. Zhou S, Hu W, Deng X, Ma Z, Chen L, Huang C, et al. Overexpression of the wheat aquaporin gene, TaAQP7, enhances drought tolerance in transgenic tobacco. PLoS One. 2012;7(12):e52439.

11. Hanba YT, Shibasaka M, Hayashi Y, Hayakawa T, Kasamo K, Terashima I, et al. Overexpression of the barley aquaporin $\mathrm{HVPIP}$; 1 increases internal $\mathrm{CO}_{2}$ conductance and $\mathrm{CO}_{2}$ assimilation in the leaves of transgenic rice plants. Plant and Cell Physiology. 2004;45(5):521-9.

12. Wang X, Cai H, Li Y, Zhu Y, Ji W, Bai X, et al. Ectopic overexpression of a novel Glycine soja stressinduced plasma membrane intrinsic protein increases sensitivity to salt and dehydration in transgenic Arabidopsis thaliana plants. Journal of Plant Research. 2015;128(1):103-13.

13. Jang JY, Lee SH, Rhee JY, Chung GC, Ahn SJ, Kang H. Transgenic Arabidopsis and tobacco plants overexpressing an aquaporin respond differently to various abiotic stresses. Plant Molecular Biology. 2007;64(6):621-32.

14. Lee HK, Cho SK, Son O, Xu Z, Hwang I, Kim WT. Drought stress-induced Rma1H1, a RING membraneanchor E3 ubiquitin ligase homolog, regulates aquaporin levels via ubiquitination in transgenic Arabidopsis plants. The Plant Cell. 2009;21:622-41.

15. Azad AK, Ahmed J, Alum MA, Hasan MM, Ishikawa T, Sawa Y, et al. Genome-wide characterization of major intrinsic proteins in four grass plants and their non-aqua transport selectivity profiles with 
comparative perspective. PLoS One. 2016;11(6):e0157735.

16. Xu B, Sathitsuksanoh N, Tang Y, Udvardi MK, Zhang J-Y, Shen Z, et al. Overexpression of AtLOV1 in switchgrass alters plant architecture, lignin content, and flowering time. PLoS One. 2012;7(12):e47399.

17. Xu B. Genetic Improvement of Switchgrass Cell Wall Content, Leaf Angle and Flowering Time [Dissertation]: Virginia Tech; 2011.

18. Sade N, Gebretsadik M, Seligmann R, Schwartz A, Wallach R, Moshelion M. The role of tobacco aquaporin1 in improving water use efficiency, hydraulic conductivity, and yield production under salt stress. Plant Physiology. 2010;152(1):245-54.

19. Ariani A, Francini A, Andreucci A, Sebastiani L. Over-expression of AQUA1 in Populus alba Villafranca clone increases relative growth rate and water use efficiency, under Zn excess condition. Plant Cell Reports. 2016;35(2):289-301.

20. Caldeira CF, Bosio M, Parent B, Jeanguenin L, Chaumont F, Tardieu F. A hydraulic model is compatible with rapid changes in leaf elongation under fluctuating evaporative demand and soil water status. Plant Physiology. 2014;164(4):1718-30.

21. Nada RM, Abogadallah GM. Aquaporins are major determinants of water use efficiency of rice plants in the field. Plant Science. 2014;227:165-80.

22. Thakur PS, Rai VK. Effect of water stress on protein content in two maize cultivars differing in drought resistance. Biologia Plantarum. 1982;24(2):96-100.

23. Jiang Y, Yao Y, Wang Y. Physiological response, cell wall components, and gene expression of switchgrass under short-term drought stress and recovery. Crop Science. 2012;52:2718-27.

24. van der Weijde T, Huxley L, Hawkins S, Sembiring E, Farrar K, Dolstra O, et al. Impact of drought stress on growth and quality of miscanthus for biofuel production. GCB Bioenergy. 2016;9:770-82.

25. Lopez F, Bousser A, Sissoëff I, Gaspar M, Lachaise B, Hoarau J, et al. Diurnal regulation of water transport and aquaporin gene expression in maize roots: contribution of PIP2 proteins. Plant and Cell Physiology. 2003;44(12):1384-95.

26. Zhang FP, Sussmilch F, Nichols DS, Cardoso AA, Brodribb TJ, Sam MA. Leaves, not roots or floral tissue, are the main site of rapid, external pressure-induced ABA biosynthesis in angiosperms. Journal of experimental botany. 2018;69(5):1261-7.

27. Fetter K, Van Wilder V, Moshelion M, Chaumont F. Interactions between plasma membrane aquaporins modulate their water channel activity. The Plant Cell. 2004;16(1):215-28.

28. Zelazny E, Borst JW, Muylaert M, Batoko H, Hemminga MA, Chaumont F. FRET imaging in living maize cells reveals that plasma membrane aquaporins interact to regulate their subcellular localization. Proceedings of the National Academy of Sciences. 2007;104(30):12359-64.

29. Bellati J, Champeyroux C, Hem S, Rofidal $₫$ Valérie, Krouk冈Gabriel. Novel aquaporin regulatory mechanisms revealed by interactomics. Molecular \& Cellular Proteomics. 2016;15(11):3473-87. 
30. di Pietro M, Vialaret J, Li G-W, Hem S, Prado K, Rossignol M, et al. Coordinated post-translational responses of aquaporins to abiotic and nutritional stimuli in Arabidopsis roots. Molecular \& Cellular Proteomics. 2013;12(12):3886-97.

31. Gomes A, da Silva IV, Rodrigues CMP, Castro RE, Soveral G. The emerging role of microRNAs in aquaporin regulation. Front Chem. 2018;6:238-

32. Pou A, Jeanguenin L, Milhiet T, Batoko H, Chaumont Fo, Hachez C. Salinity-mediated transcriptional and post-translational regulation of theArabidopsisaquaporin PIP2;7. Plant Molecular Biology. 2016;92(6):731-44.

33. Xu B, Huang L, Shen Z, Welbaum GE, Zhang X, Zhao B. Selection and characterization of a new switchgrass (Panicum virgatum L.) line with high somatic embryogenic capacity for genetic transformation. Scientia horticulturae. 2011;129(4):854-61.

34. Yuan S, Xu B, Zhang J, Xie Z, Cheng Q, Yang Z, et al. Comprehensive analysis of CCCH-type zinc finger family genes facilitates functional gene discovery and reflects recent allopolyploidization event in tetraploid switchgrass. BMC genomics. 2015;16(1):129.

35. Xu B, Escamilla-Treviño LL, Sathitsuksanoh N, Shen Z, Shen H, Percival Zhang YH, et al. Silencing of 4-coumarate: coenzyme A ligase in switchgrass leads to reduced lignin content and improved fermentable sugar yields for biofuel production. New Phytologist. 2011;192(3):611-25.

36. Hardin CF, Fu C, Hisano H, Xiao X, Shen H, Stewart CN, et al. Standardization of switchgrass sample collection for cell wall and biomass trait analysis. BioEnergy Research. 2013;6(2):755-62.

37. Dubois M, Gilles KA, Hamilton JK, Rebers PA, Smith F. Colorimetric method for determination of sugar and related substances Analytical Chemistry. 1956;28 350-6.

38. Viles FJ, Silverman L. Determination of starch and cellulose with anthrone. Analytical Chemistry. 1949;21:950-3.

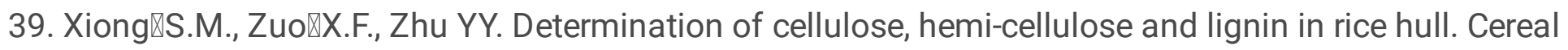
\& Feed Industry. 2005;8:40-1.

40. Krishnamoorthy U, Muscato TV, Sniffen CJ, Van Soest PJ. Nitrogen fractions in selected feedstuffs. Journal of Dairy Science. 1982;65:217-25.

41. Blum A, Ebercon A. Cell membrane stability as a measure of drought and heat tolerance in wheat. Crop Science. 1981;21(1):43-7.

42. Zhang J, Yu G, Wen W, Ma X, Xu B, Huang B. Functional characterization and hormonal regulation of the PHEOPHYTINASE gene LPPPH controlling leaf senescence in perennial ryegrass. Journal of experimental botany. 2015;67(3):935-45.

43. Hu L, Wang Z, Du H, Huang B. Differential accumulation of dehydrins in response to water stress for hybrid and common bermudagrass genotypes differing in drought tolerance. Journal of plant physiology. 2010;167(2):103-9.

44. Tamura K, Stecher G, Peterson D, Filipski A, Kumar S. MEGA6: molecular evolutionary genetics analysis version 6.0. Molecular biology and evolution. 2013:mst197. 


\section{Figures}

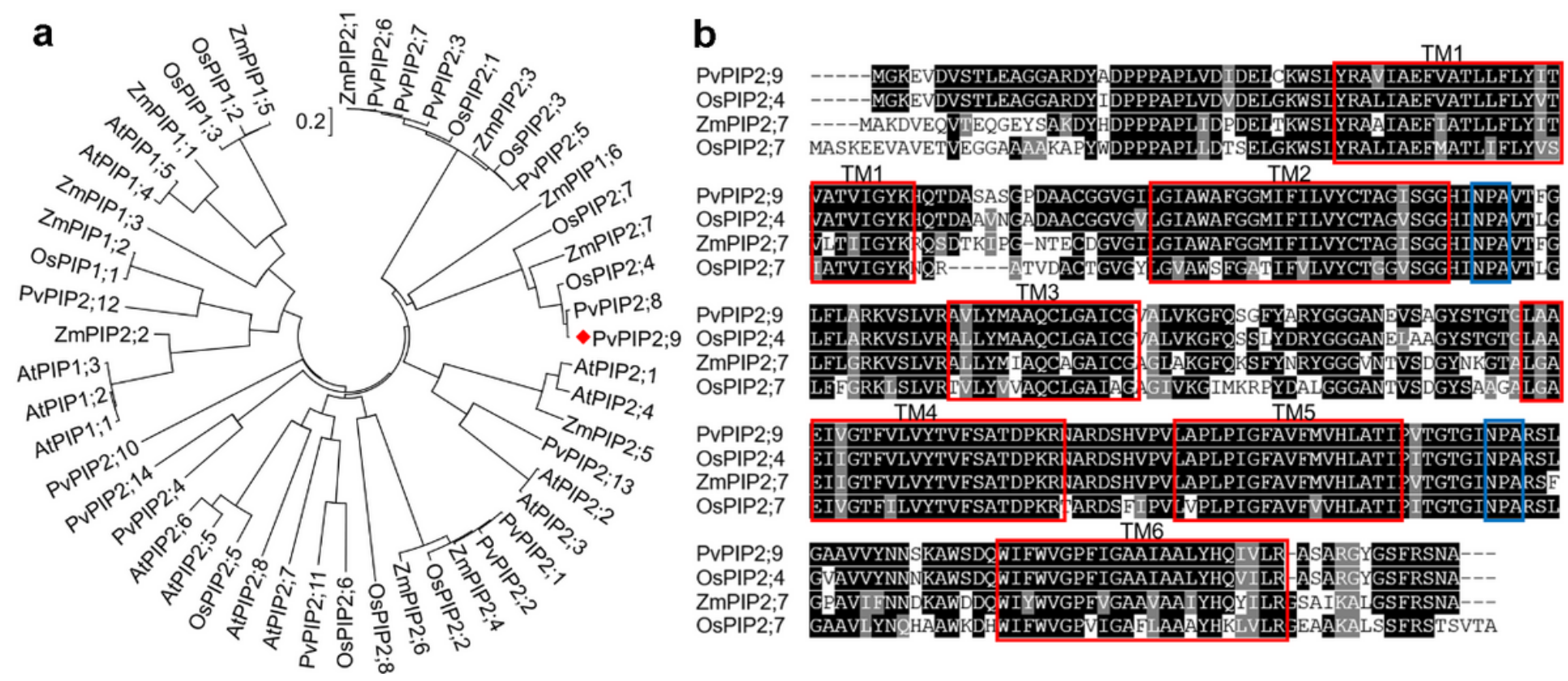

\section{Figure 1}

Phylogenetic tree and multiple alignment of PvPIP2;9 and other PIP2s. (A) The Neighbor-Joining evolutionary tree was built with PIP1 and PIP2 proteins in switchgrass (PvPIPs), Arabidopsis (AtPIPs), rice (OsPIPs) and maize (ZmPIPs) using MAGA6 (44) with the sum of branch length $=24.55096375$. The tree is drawn to scale and there were a total of 264 positions in the final dataset. (B) Multiple sequence alignment of PvPIP2;9 with its closest orthologues, showing that these PIP2s shared conserved TM domains and NPA residues. 

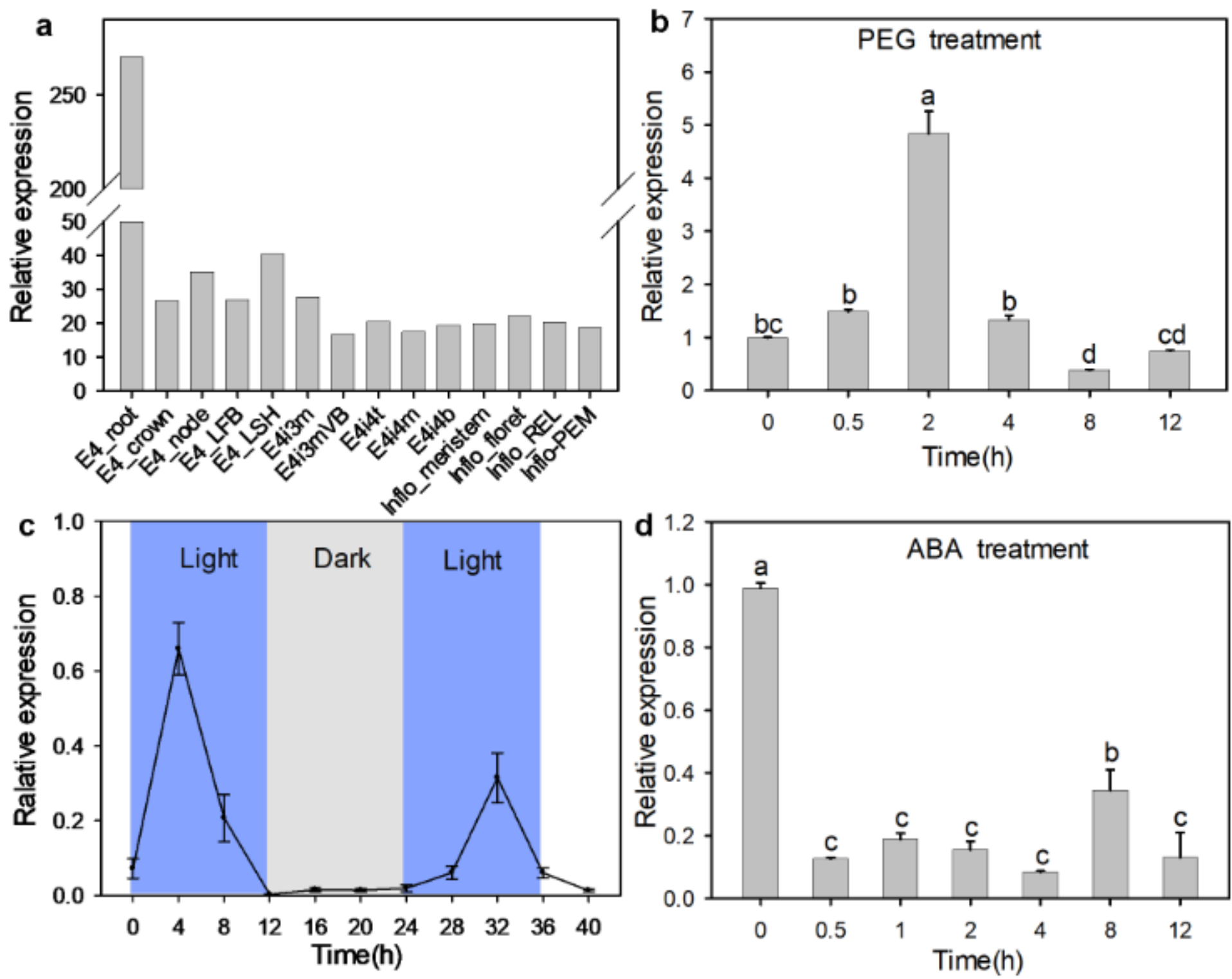

Figure 2

Expression pattern of PvPIP2;9. (A) Transcripts levels of PvPIP2;9 in different organ/tissues. (B-D) qRTPCR measurement of PvPIP2;9 relative expression levels during $40 \mathrm{hrs}$, and relative expression of PvPIP2;9 after treatment with $20 \%$ PEG6000 or $100 \mu \mathrm{M}$ ABA. The relative expression of the gene was calculated by normalizing the relative expression of PvPIP2;9 under treatment against those under normal growth condition at the same time point. Data are means \pm SE. Different letters above bars represent significant difference at $P<0.05$. Data in $(A)$ was were adopted from PviGEA database and the abbreviations were as follows. E4i4b: Bottom 1/5 fragment of the 4th internode; E4i4t: Top 1/5 fragment of the 4th internode; E4i4m: Middle 1/5 fragment of the 4th internode 4; E4-LFB: Pooled leaf blade from plant ; E4-LSH: Pooled leaf sheath; Inflo-REL: Rachis and branch elongation of inflorescence (50-150 $\mathrm{mm})$; Inflo-PEM: Panicle emergence of inflorescence $(>200 \mathrm{~mm})$; E4i3m: Middle 1/5 fragment of the 3rd internode; E4i3m-VB: Vascular bundle isolated from 1/5 fragment of the 3rd internode; E4-root: Whole 
root system; E4-crown: Whole crown; E4-node: Pooled nodes; Inflo-meristem: Inflorescence meristem (0.5$3.0 \mathrm{~mm}$ ); Inflo-floret: Floret of inflorescence when glumes are $10-20 \mathrm{~mm}$.
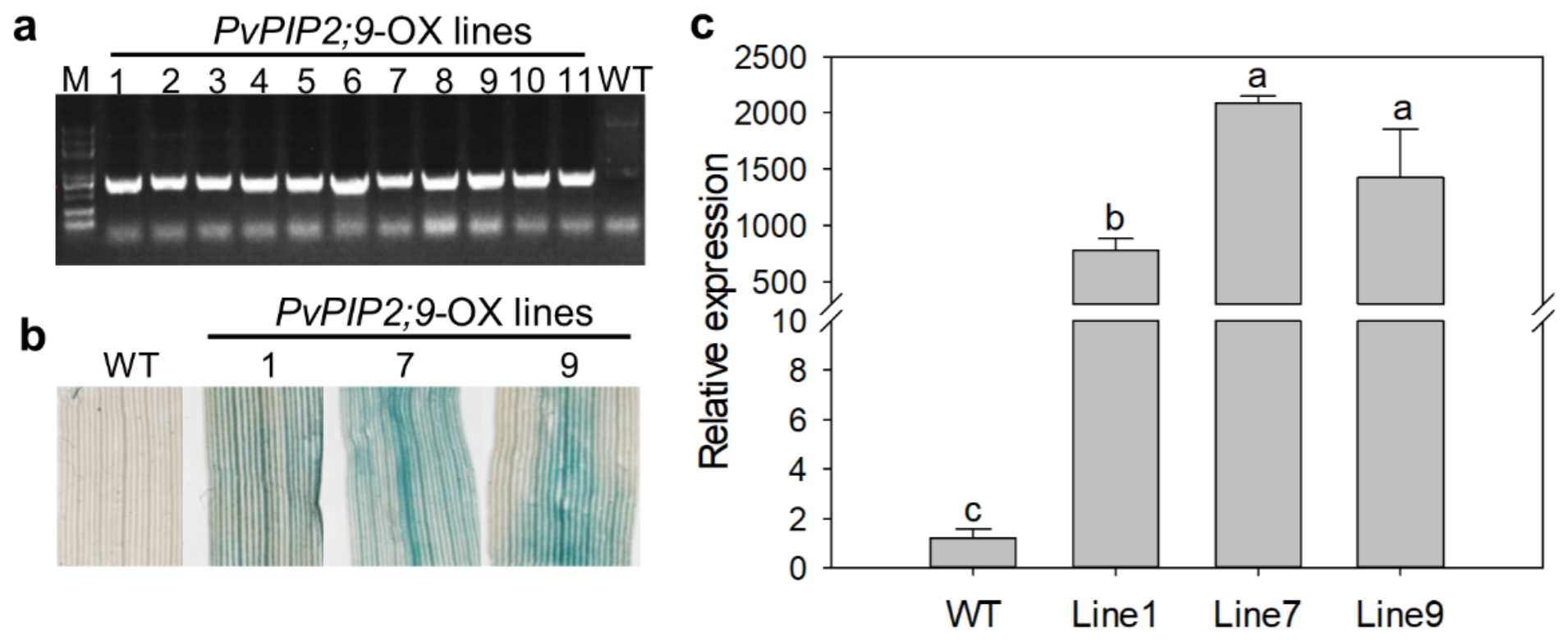

\section{Figure 3}

Identification of PvPIP2;9 transgenic switchgrass lines. (A) Confirmation of the T-DNA insertion with PCR for the presence of HPTII gene. (B) GUS staining and (C) relative expression of PvPIP2;9 in transgenic lines by qRT-PCR. Data in $(C)$ are means $\pm S E$, and different letters above bars represent significant difference at $\mathrm{P}<0.05$. 


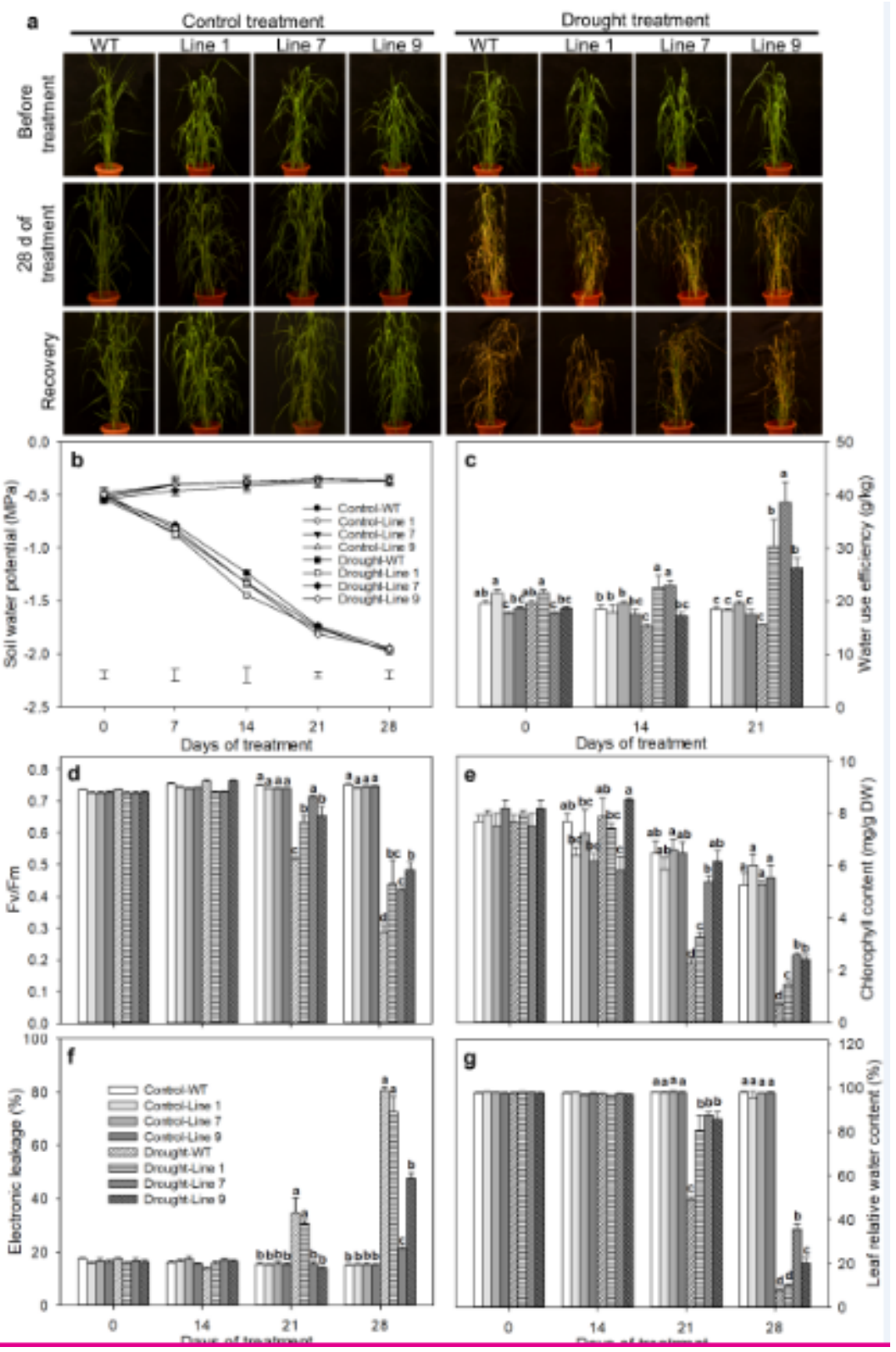

Figure 4

Comparison of drought tolerance between WT and PvPIP2;9 transgenic switchgrass lines. (A) Phenotypes of WT and transgenic lines before and after 28 days of drought treatment, and after 10 days of rewatering (recovery). (B) Soil water potential in pots for the well-watered control and for those under the drought treatment. (C-G) Dynamic changes of WUE (C), Fv/Fm (D), Chl contents (E), EL (F), and RWC (G) of the WT and transgenic lines during the drought treatment. The second fully expanded leaves from the top were used for the data analysis. Data are means \pm SE. Different letters above bars represent significant difference at $\mathrm{P}<0.05$. 

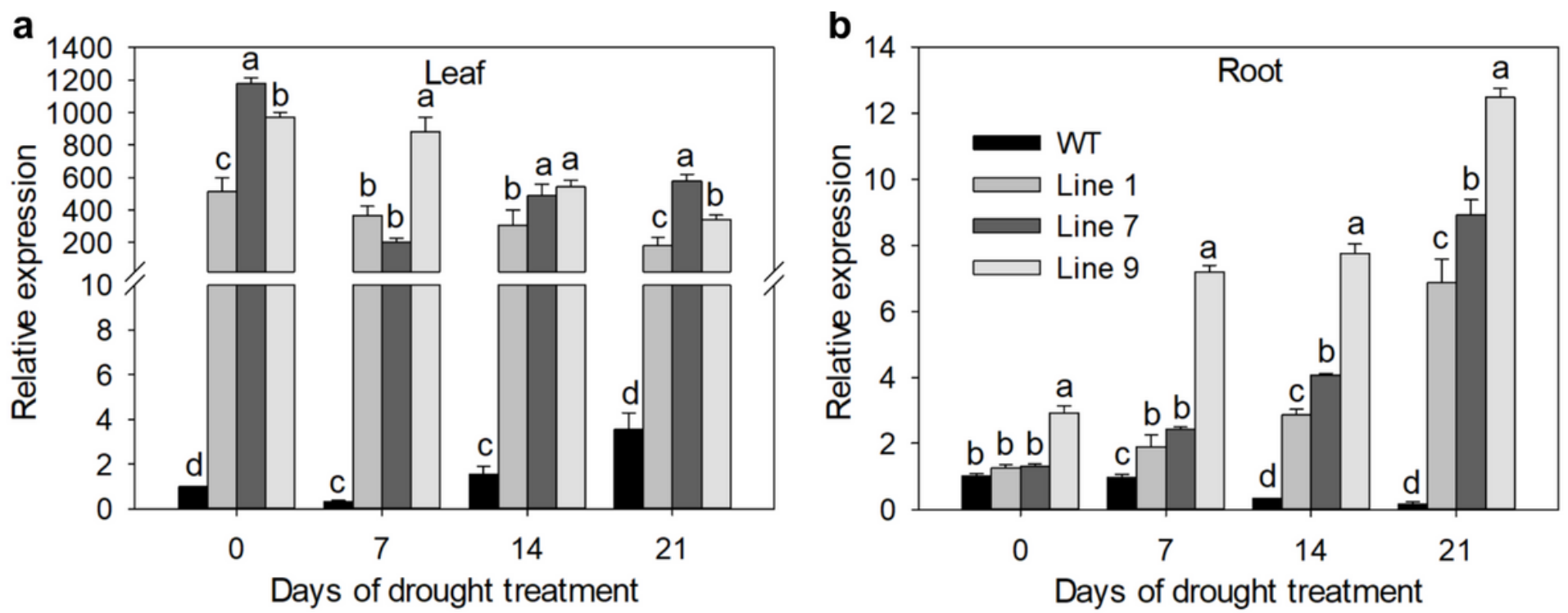

Figure 5

Relative expression of PvPIP2;9 in leaves and roots during 21 days of drought using qRT-PCR. Data are means \pm SE. Different letters above bars represent significant difference at $P<0.05$.
WT
Line 1
Line 7
Line 9

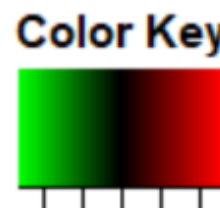

$\begin{array}{lll}-2 & 0 & 2\end{array}$
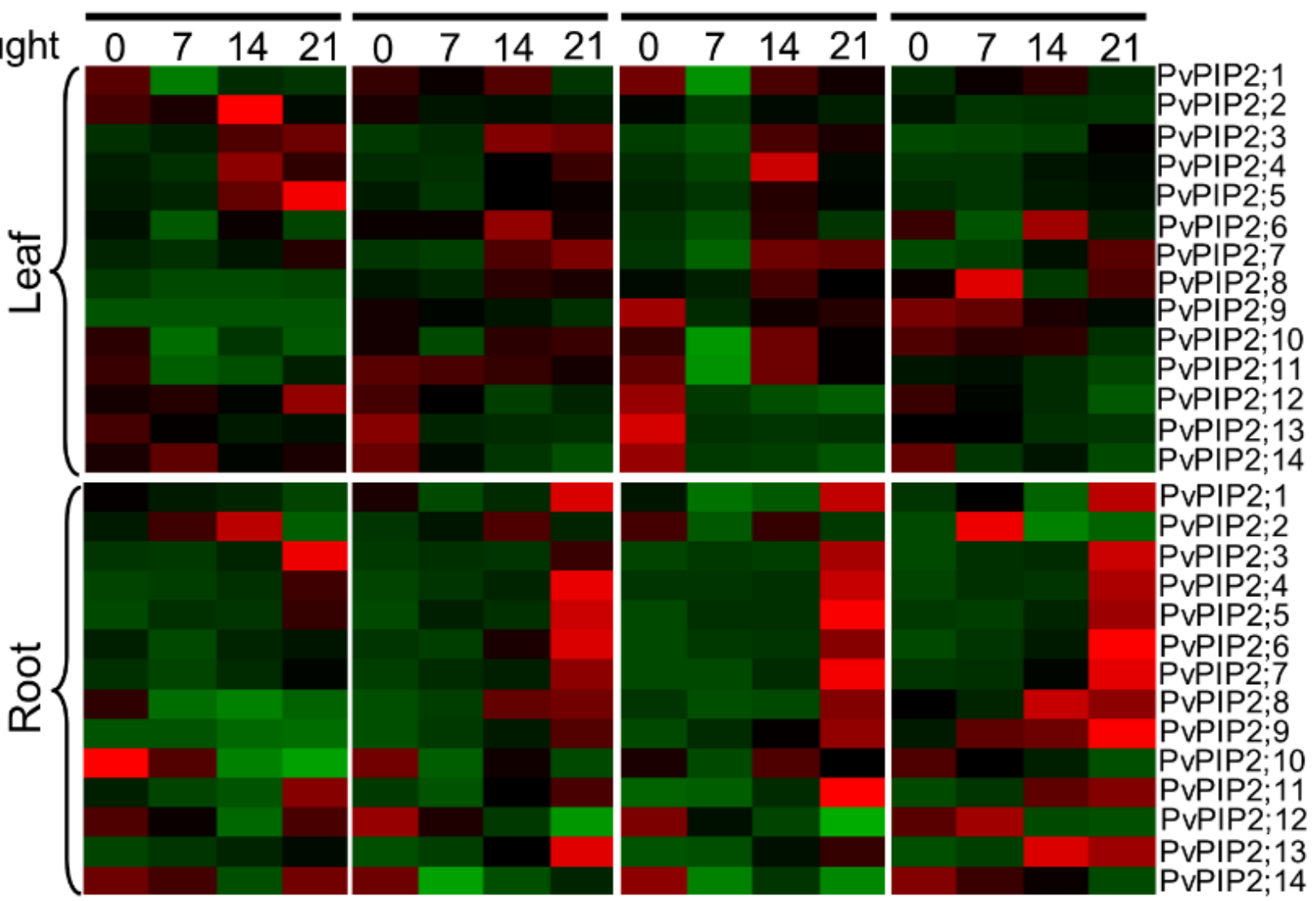

Figure 6 
Relative expression of other PIP2 subfamily genes in leaves and roots during 21 days of drought using qRT-PCR. Data of qRT-PCR were converted into the heatmap using R-package software (version 3.3.1) and the quantitative color scheme was based on log2 of each PIP2 subfamily genes' relative expression levels.

\section{Supplementary Files}

This is a list of supplementary files associated with this preprint. Click to download.

- TableS1.docx

- Fig.S1.xIsx 